\title{
An Effective Rotor Current Controller for Unbalanced Stand-Alone DFIG Systems in the Rotor Reference Frame
}

\author{
Van-Tung Phan*, Hong-Hee Lee ${ }^{\dagger}$, and Tae-Won Chun* \\ ${ }^{\dagger}$ School of Electrical Engineering, University of Ulsan, Ulsan, Korea
}

\begin{abstract}
This paper presents an effective rotor current controller for variable-speed stand-alone doubly fed induction generator (DFIG) systems feeding an unbalanced three-phase load. The proposed current controller is developed based on proportional plus two resonant regulators, which are tuned at the positive and negative slip frequencies and implemented in the rotor reference frame without decomposing the positive and negative sequence components of the measured rotor current. In addition, the behavior of the proposed controller is examined in terms of control performance and stability with respect to rotor speed variations, i.e., slip frequency variations. Simulations and experimental results are shown to validate the robustness and effectiveness of the proposed control method.
\end{abstract}

Key Words: Doubly-fed induction generator (DFIG), Resonant controller, Stand-alone wind system, Unbalanced loads, Variablespeed wind system

\section{INTRODUCTION}

Wind energy has been known as an important and promising resource of renewable energy. An effective and suitable selection from the various generators for wind turbine systems should be considered carefully. Among the different wind generators, doubly fed induction generators (DFIG) have been widely used for many variable-speed wind turbines for both grid-connected and stand-alone wind power generation systems [1]-[4]. The main advantages of a DFIG are well-known. These include variable speed operation, decoupled active and reactive power capability, and a reduced power rating around $20-30 \%$ of a machine's rated power.

Most DFIG studies in the literature have investigated the symmetrical network voltages or the balanced loads. In reality, however, unsymmetrical conditions such as network disturbances, unbalanced grid voltages, and unbalanced loads happen much more frequently and therefore degrade overall control performance and efficiency. For such DFIG systems, if the stator voltage imbalance is not fully compensated by an appropriate control algorithm, the stator voltage can be highly unbalanced. Even with a small stator voltage imbalance such a scenario will create unequal heating on the stator windings, power loss, and torque or power pulsations, which reduce the lifetime of the generator.

Many control systems for a grid-connected DFIG system

Manuscript received Mar. 29, 2010; revised Aug. 25, 2010

† Corresponding Author: hhlee@mail.ulsan.ac.kr

Tel: +82-52-259-2187, Fax: +82-52-259-2186, Univ. of Ulsan

* School of Electrical Engineering, University of Ulsan, Korea under unbalanced grid voltage conditions have been widely investigated in the literatures [5]-[8]. In [5], a detailed investigation on the impact of an unbalanced stator voltage on the pulsations of DFIG stator and rotor currents, torque, and stator active and reactive powers was presented. However, because of limited and insufficient control variables on the rotorside converter (RSC), it was impossible to obtain adequate control for reducing both torque and active power oscillations. To overcome this, a dual-sequence field-oriented current controller was proposed for both the RSC and the grid-side converter (GSC) within an unbalanced DFIG system [6]. The paper used the so-called "signal delay cancellation" method to separate the positive and negative sequences. However, the control performance was degraded due to a time delay caused by the additional decomposition process. In [7], [8], the direct power control method with prominent features was developed to achieve good compensation results in a DFIG under unbalanced operation. A new method of calculating the stator active and reactive power was proposed in [7] to avoid torque oscillations, whereas [8] developed a new algorithm to achieve a sinusoidal stator current exchange with the grid based on an appropriate power reference generation strategy in the RSC. In [9] and [10], the modeling and control of DFIG based on the GSC for unbalanced operation were investigated for both grid-connected and stand-alone applications. However, no modifications were applied to the RSC. Furthermore, the current control scheme was also based on the decomposition of the positive and negative sequences, which made the overall computation process more complicated. 


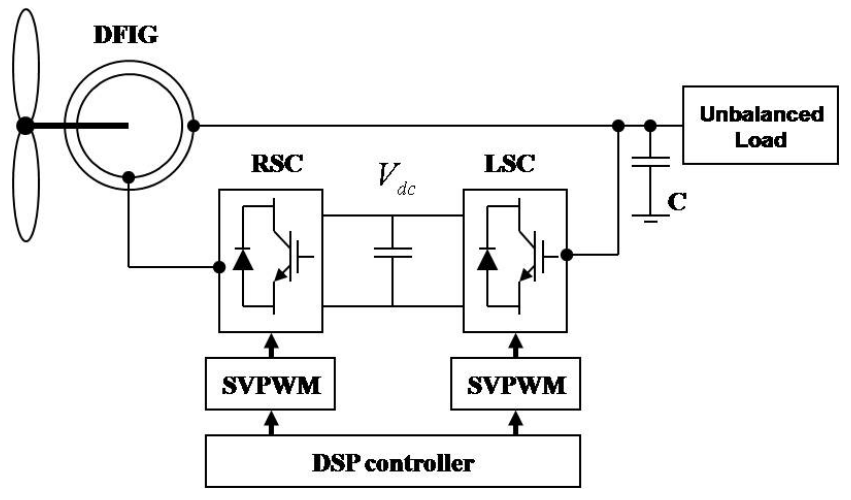

Fig. 1. Unbalanced stand-alone DFIG-based wind systems.

Studies associated with the DFIG above have been developed based on proportional-integral (PI) controllers that are simple and effective in use. However, these have disadvantages of steady state errors in amplitude and phase when regulating the AC quantities. To overcome this drawback, a resonant controller has been considered as a promising solution, and proportional plus resonant regulators have been proposed in the literature for current control at the fundamental frequency and the selective harmonic frequencies [11]-[13]. Due to the infinite gain at a selected resonant frequency, such a controller is capable of completely eliminating the steady-state control error at that specific frequency. Hence it offers good improvement when compared to PI or PID controllers. In [14], an improved control strategy using a PI-resonant controller was proposed in the positive rotating reference frame for an unbalanced DFIG system. The steady state performance of the rotor currents was effectively achieved, and the stator output voltages were also compensated well. However, the major disadvantage of this strategy is that several coordinate transformations are required for the rotor current to be controlled in the synchronous frame, which can introduce errors due to inaccurate frame identification. This disadvantage can be removed if the rotor currents can be controlled at the rotor reference frame instead of the positive synchronous reference frame. However, it has been difficult to achieve satisfactory control performance for the rotor current in the rotor reference frame because the rotor reference frame varies due to wind speed changes in the wind power generating systems.

In this paper, we develop an effective control strategy using a proportional plus two resonant $(\mathrm{P} 2 \mathrm{R})$ regulators for a variable-speed stand-alone DFIG system with an unbalanced load. The two resonant regulators are tuned at the positive and negative slip frequencies. The rotor currents are controlled directly without involving coordinate transformations for the measured rotor currents. The proposed control scheme is implemented solely with respect to the RSC of the DFIG. To demonstrate the feasibility of the controller in practical DFIG systems, a further investigation on the control performance and stability of the control scheme with respect to slip speed variations is also presented in this paper. The robustness and effectiveness of the proposed current controller are verified by simulations and experimental verifications.

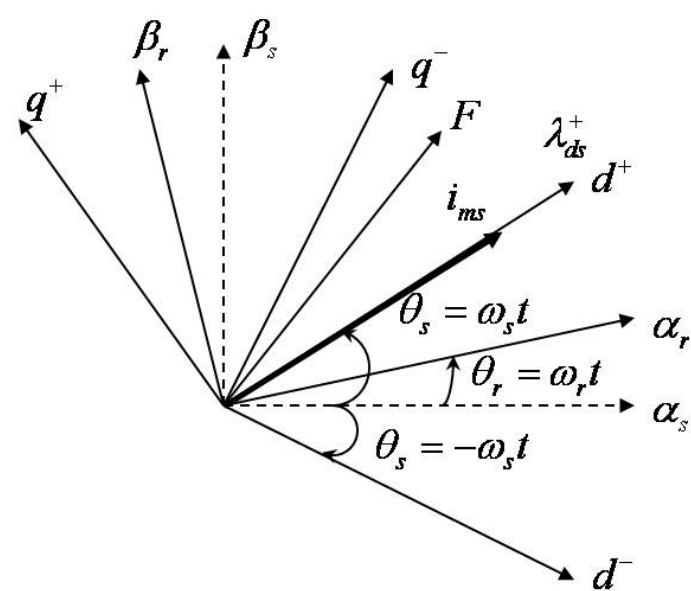

Fig. 2. The vector diagram representing the relationship between different reference frames.

\section{THE PROPOSED CONTROL TOPOLOGY}

The control and operation of balanced stand-alone DFIG systems are described in [2]. In this section, an analysis is performed on a vector-controlled DFIG-based variablespeed wind energy system that supplies electrical energy to an unbalanced stand-alone load or an isolated grid. Under this load condition, the stator voltage, current, torque, flux, and power include both positive and negative sequence components that cause fluctuations in the positive and negative slip frequencies in the rotor reference frame. The following subsection will describe the control strategy implemented in the RSC to compensate for unbalanced stator voltages. In addition, a method of calculating the reference rotor currents for the proposed current controllers is also outlined.

\section{A. Dynamic model of a DFIG}

The control structure is developed based on the induction machine dynamic model in the rotor reference frame. The main purpose of the RSC is to control the stator voltage magnitude and frequency. In stand-alone operations, a DFIGbased wind energy system has to supply a constant voltage and frequency to the stator terminals irrespective of variations in the rotor speed. The control system for a DFIG under an unbalanced load is developed based on the stator fluxoriented vector control strategy. Fig. 2 shows a vector diagram that represents the relationship between a stator stationary frame $\left(\alpha_{s} \beta_{s}\right)$, a rotor frame $\left(\alpha_{r} \beta_{r}\right)$ rotating with an angular speed $\left(\omega_{r}\right)$, a positive frame $\left(d q^{+}\right)$rotating with a positive angular speed $\left(\omega_{s}\right)$, and a negative frame $\left(d q^{-}\right)$rotating with a negative angular speed $\left(-\omega_{s}\right)$. The superscripts + and represent positive and negative synchronous reference frames, respectively. The vector $F$ denotes the value of the voltage, the current, or the flux in the stator flux-oriented reference frame.

Under an unbalanced load condition, the most effective method to analyze a DFIG model is to use a positive reference frame rotating at a speed of $\left(\omega_{s}\right)$ and a negative reference frame rotating at a speed of $\left(-\omega_{s}\right)$. According to Fig. 2, the relationship between the vector $F$ in different frames is 


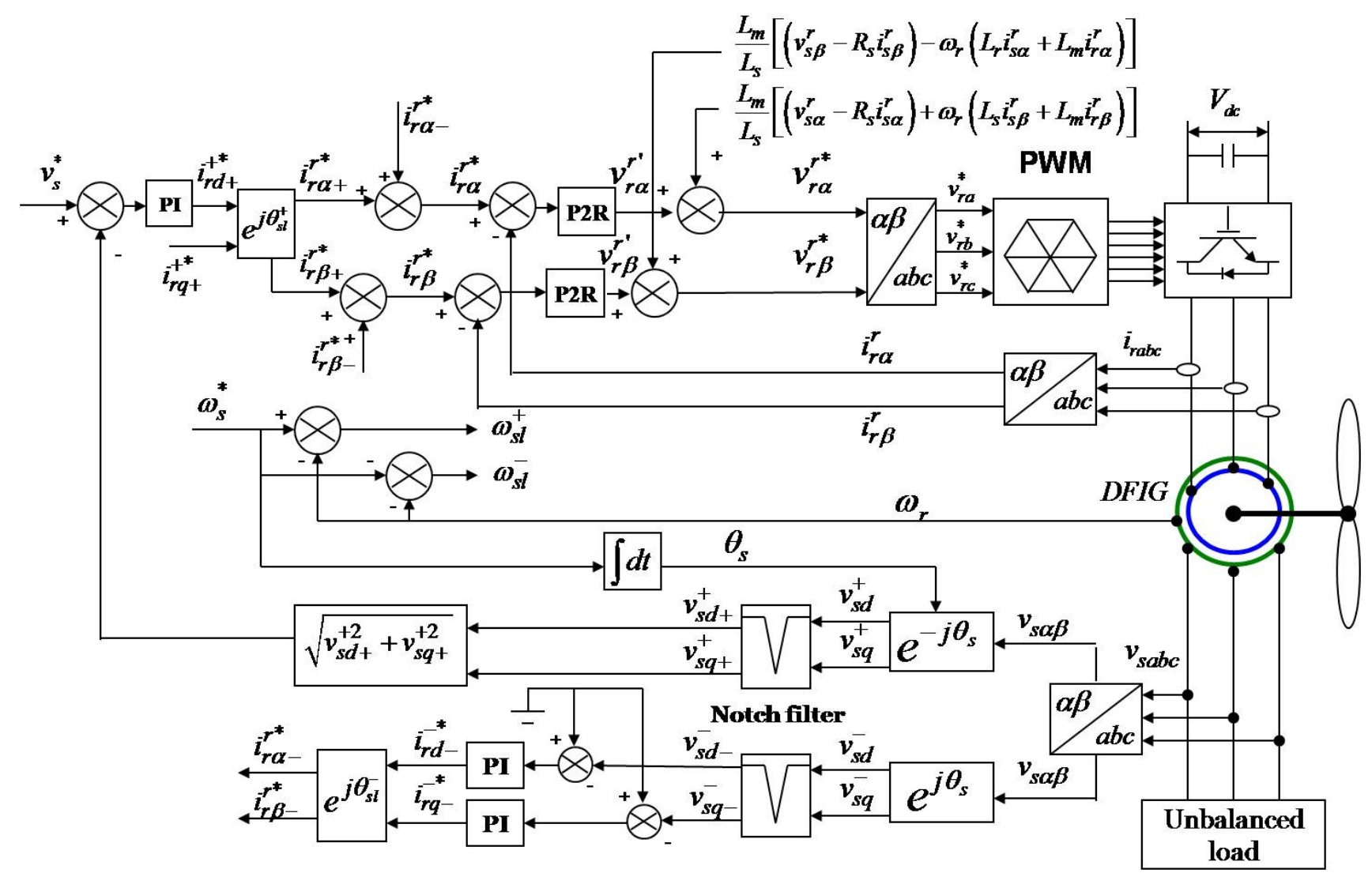

Fig. 3. The proposed current control scheme for the RSC of a DFIG under an unbalanced load condition.

illustrated as follows:

$$
\begin{aligned}
& F_{\alpha_{r} \beta_{r}}=F_{d q}^{+} e^{j \omega_{s l}^{+} t}=F_{d q}^{-} e^{-j \omega_{s l}^{-} t} \\
& F_{d q}^{+}=F_{d q}^{-} e^{-j 2 \omega_{s} t}
\end{aligned}
$$

In addition, the stator and rotor current, the voltage, and the flux vectors $F$ can be expressed in the rotor rotating reference frame $\left(\alpha_{r} \beta_{r}\right)$ with their respective positive and negative sequences, given as:

$$
F_{\alpha_{r} \beta_{r}}=F_{\alpha_{r} \beta_{r}+}+F_{\alpha_{r} \beta_{r}-}=F_{d q+}^{+} e^{j \omega_{s l}^{+} t}+F_{d q-}^{-} e^{j \omega_{s l}^{-} t}
$$

where the subscripts + and - represent the positive and negative sequence components, respectively. The slip frequencies are calculated as $\omega_{s l}^{+}=\omega_{s}-\omega_{r}$ and $\omega_{s l}^{-}=-\omega_{s}-\omega_{r}$.

According to (2), the quantities in the rotor reference frame are the sum of the AC components with frequencies of $\omega_{s l}^{+}$and $\omega_{s l}^{-}$. As mentioned previously, the control target is developed based on the rotor reference frame and therefore the dynamic DFIG equations are described as follows:

$$
\begin{gathered}
v_{s \alpha \beta}^{r}=R_{s} i_{s \alpha \beta}^{r}+\frac{d \lambda_{s \alpha \beta}^{r}}{d t}+j \omega_{r} \lambda_{s \alpha \beta}^{r} \\
v_{r \alpha \beta}^{r}=R_{r} i_{r \alpha \beta}^{r}+\frac{d \lambda_{r \alpha \beta}^{r}}{d t} \\
\lambda_{s \alpha \beta}^{r}=L_{s} i_{s \alpha \beta}^{r}+L_{m} i_{r \alpha \beta}^{r} \\
\lambda_{r \alpha \beta}^{r}=L_{r} i_{r \alpha \beta}^{r}+L_{m} i_{s \alpha \beta}^{r} .
\end{gathered}
$$

From (3)-(6), the rotor voltages in the rotor reference frame can be expressed as:

$$
\begin{aligned}
& v_{r \alpha}^{r}=R_{r} i_{r \alpha}^{r}+\sigma L_{r} \frac{d i_{r \alpha}^{r}}{d t} \\
& +\frac{L_{m}}{L_{s}}\left[\left(v_{s \alpha}^{r}-R_{s} i_{s \alpha}^{r}\right)+\omega_{r}\left(L_{s} i_{s \beta}^{r}+L_{m} i_{r \beta}^{r}\right)\right] \\
& v_{r \beta}^{r}=R_{r} i_{r \beta}^{r}+\sigma L_{r} \frac{d i_{r \beta}^{r}}{d t} \\
& +\frac{L_{m}}{L_{s}}\left[\left(v_{s \beta}^{r}-R_{s} i_{s \beta}^{r}\right)-\omega_{r}\left(L_{s} i_{s \alpha}^{r}+L_{m} i_{r \alpha}^{r}\right)\right]
\end{aligned}
$$

where $R_{S}$ is the stator resistance, $L_{S}$ is the stator inductance, $R_{r}$ is the rotor resistance, $L_{r}$ is the rotor inductance, $L_{m}$ is the mutual inductance, $\sigma=1-L_{m}^{2} /\left(L_{r} L_{s}\right)$ represents the total leakage factor, $\lambda_{s \alpha \beta}^{r}$ is the stator flux, and $\lambda_{r \alpha \beta}^{r}$ is the rotor flux in the rotor reference frame. The superscript " $r$ " denotes the rotor reference frame $\left(\alpha_{r} \beta_{r}\right)$.

A block diagram of a stand-alone DFIG with the proposed stator voltage compensation method is presented in Fig. 3. The magnitude of the stator voltage is controlled directly with a given specific command value $v_{s}^{*}$ by adding an external voltage control loop. The specific magnitude of the stator voltage is obtained from the positive sequence components of the measured voltage signals, given as:

$$
v_{s}=\sqrt{v_{s d+}^{+2}+v_{s q+}^{+2}} .
$$

The stator voltage control loop is implemented by using a PI controller in order to regulate the stator voltages in a stable manner. This control loop mainly aims to reject the 
voltage variations caused by the effects of electric loads or speed changes.

\section{B. Identification of reference rotor currents in the rotor refer- ence frame}

The proposed P2R controller is used to precisely track the reference rotor currents, which are determined based on four rotor current components, i.e., $i_{r d+}^{+*}, i_{r q+}^{+*}, i_{r d-}^{-*}$, and $i_{r q-}^{-*}$. The desired control target is to eliminate the negative sequence components, i.e., $v_{s d-}^{-}$and $v_{s q-}^{-}$, in the generated stator voltages. Therefore, four controllable rotor current components are implemented in the RSC to satisfy the system operation effectively. As shown in Fig. 3, the reference negative sequence components of the rotor currents, i.e., $i_{r d-}^{-*}$ and $i_{r q-}^{-*}$, are the outputs of the two PI controllers. These controllers are used to drive the negative sequence components of the stator voltage to zero in the negative rotating reference frame. To obtain $v_{s d-}^{-}$ and $v_{s q-}^{-}$, two notch filters are used to extract the values from their respective components in the negative rotating reference frame.

In order to apply the $\mathrm{P} 2 \mathrm{R}$ current controller in the rotor reference frame, the four reference rotor current values previously determined are transformed into coordinates $\alpha_{r} \beta_{r}$ using the synchronous angles $\theta_{s l}^{+}=\theta_{s}-\theta_{r}$ and $\theta_{s l}^{-}=-\theta_{s}-\theta_{r}$, calculated as:

$$
i_{r \alpha \beta}^{r *}=i_{r \alpha \beta+}^{r *}+i_{r \alpha \beta-}^{r *}=i_{r d q+}^{+*} e^{j \theta_{s l}^{+}}+i_{r d q-}^{-*} e^{j \theta_{s l}^{-}} .
$$

\section{THE PROPOSED P2R CURRENT CONTROLLER}

\section{A. The Prominent Features of the P2R Regulator}

Once the reference rotor currents in the rotor rotating reference frame in (10) are obtained, they are controlled to achieve the control target, i.e., eliminating the stator voltage imbalance. The use of a notch filter for the purpose of decomposing the positive and the negative sequence components of the control variable causes time delays due to the computational complexity and hence it degrades the system performance. The decomposition process of the measured rotor currents can be practically implemented by a digital notch or low-pass filters. Under an unbalanced load condition, the control system for a DFIG must be precisely controlled during the transient process as well as in the steady-state. If the decomposition process takes place in the inner current control loops, the system stability and overall efficiency can be degraded significantly.

To improve the accuracy of the control system, the P2R controller in the rotor reference frame was applied to the RSC of a DFIG in this paper. One of the most prominent features of the resonant controller is that it is capable of sufficiently tracking the $\mathrm{AC}$ reference current and therefore, it can eliminate the steady-state control variable errors at chosen (resonant) frequencies. The s-domain open-loop transfer function of the proposed $\mathrm{P} 2 \mathrm{R}$ rotor current controller is defined as follows:

$$
G_{o}(s)=K_{p}+\frac{K_{r} s}{s^{2}+\left(\omega_{s l}^{+}\right)^{2}}+\frac{K_{r} s}{s^{2}+\left(\omega_{s l}^{-}\right)^{2}}
$$

where $K_{p}$ is the proportional gain that has the same function in the PI controller, $K_{r}$ denotes the resonant gain that provides

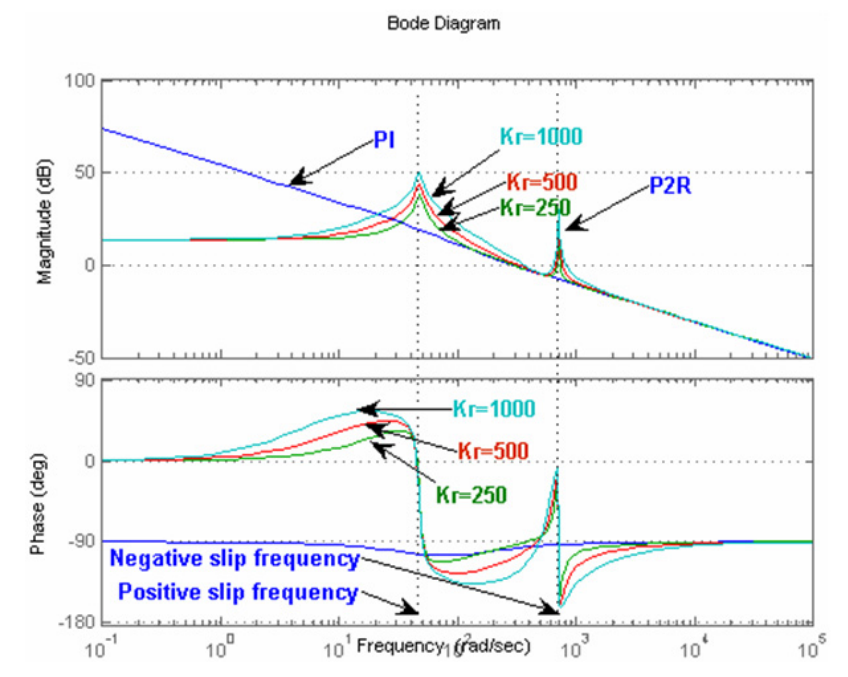

Fig. 4. Bode diagrams of open loop PI and P2R contollers at the constant slip frequencies.

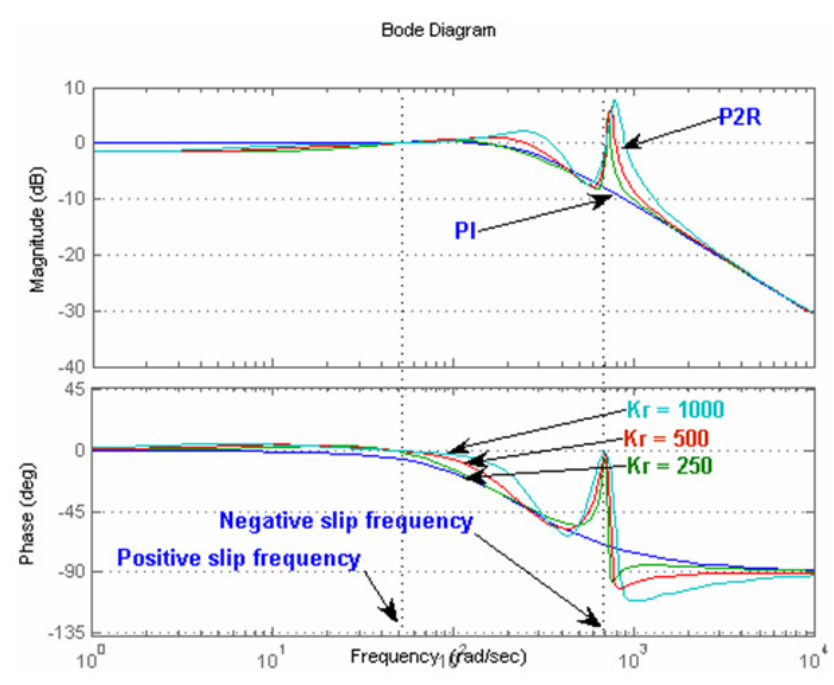

Fig. 5. Bode diagrams of closed-loop PI and P2R controllers at the constant slip frequencies.

the infinite gain for AC component tracking, and $\omega_{s l}^{+}$and $\omega_{s l}^{-}$ are the resonant frequencies at the positive and negative slip frequencies.

Fig. 4 describes the magnitude and phase characteristics of the open loop transfer functions for both the PI controller and the P2R with respect to different values of the resonant gain $K_{r}$. The large gain adjusted at the resonant frequency ensures that the steady-state errors in the rotor currents can be completely eliminated. Furthermore, the selection of the resonant gain values determines the cross-over frequency and the dynamic response of the control system. As illustrated in Fig. 4, a low $K_{r}$ gives a very narrow bandwidth, whereas a high $K_{r}$ leads to a larger bandwidth. Fig. 5 shows a bode-diagram of the closed-loop transfer functions of the P2R current controller when compared with a conventional PI controller. The gains used in both bode-diagrams are determined based on the Naslin polynomial technique, which was introduced in [15]. As shown in Fig. 5, the proposed controller with the resonant controller provides more accurate control with the 


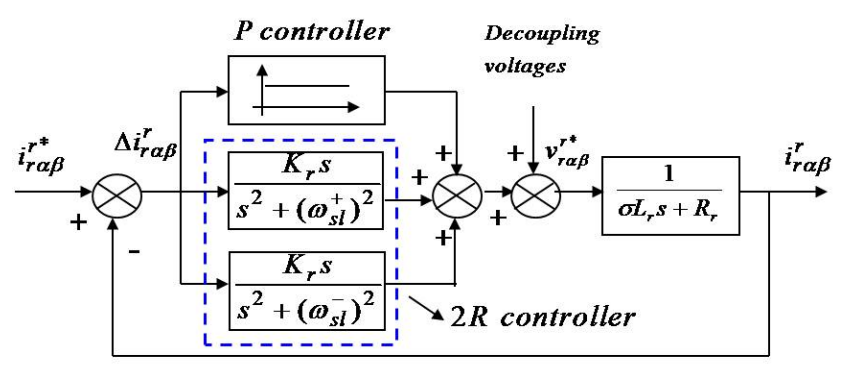

Fig. 6. The proposed P2R rotor current controller.

characteristics of unity gain $(0 \mathrm{~dB})$ and zero phase error at two resonant frequencies, i.e., $\omega_{s l}^{+}=15 \pi(\mathrm{rad} / \mathrm{s})$ and $\omega_{s l}^{-}=225 \pi$ $(\mathrm{rad} / \mathrm{s})$. In contrast, the control bandwidth of the PI controller is not sufficient to regulate at the same resonant frequencies. Besides, it can be observed that the accuracy of the proposed P2R controller when compared to the PI controller is strongly based on the performance of the resonant regulator tuned at the negative slip frequency $\omega_{s l}^{-}=225 \pi(\mathrm{rad} / \mathrm{s})$, which is much larger than the positive slip frequency $\omega_{s l}^{+}=15 \pi$ $(\mathrm{rad} / \mathrm{s})$. This can be seen clearly in Fig. 5. For the sake of simplicity, however, the positive and negative slip frequencies in Fig. 4 and Fig. 5 are identified with a constant rotor speed of $\omega_{r}=105 \pi(\mathrm{rad} / \mathrm{s})$ and a constant synchronous speed of $\omega_{s}=120 \pi(\mathrm{rad} / \mathrm{s})$. To verify the good dynamic performance of the proposed controller, further discussions associated with the variable rotor speed operation will be introduced in the next subsections.

\section{B. Analysis of Control Performance}

A closed-loop current control scheme in the RSC is described in Fig. 6. In order to determine if the proposed controller can achieve zero steady-state errors, an analytical investigation regarding its frequency response in a closed-loop system was employed. The closed-loop transfer function of the control scheme is given by:

$$
\begin{aligned}
G_{c}(s) & =\frac{i_{r \alpha \beta}^{r}}{i_{r \alpha \beta}^{r *}}=\frac{G_{o}(s)}{\left(\sigma L_{r} s+R_{r}\right)+G_{o}(s)} \\
& =\frac{K_{p} A+K_{r} s B}{A\left(\sigma L_{r} s+R_{r}\right)+K_{p} A+K_{r} s B} \\
A & =\left(s^{2}+\left(\omega_{s l}^{+}\right)^{2}\right)\left(s^{2}+\left(\omega_{s l}^{-}\right)^{2}\right) \\
B & =\left(2 s^{2}+\left(\omega_{s l}^{+}\right)^{2}+\left(\omega_{s l}^{-}\right)^{2}\right) .
\end{aligned}
$$

By substituting $s=j \omega_{s l}^{+}$and $s=j \omega_{s l}^{-}$into (12) respectively, we can see that the frequency gains of the closed-loop transfer function at the positive slip frequency $\omega_{s l}^{+}$and the negative slip frequency $\omega_{s l}^{-}$are equal to 1 . Similarly the phase errors at such frequencies are equal to 0 , as computed in (13). This means that the good performance of the control system can be obtained with unity gains and zero phase errors at different slip (resonant) frequencies.

$$
\left.G_{c}(s)\right|_{s=j \omega_{s l}^{ \pm}}=1,\left.\angle G_{c}(s)\right|_{s=j \omega_{s l}^{ \pm}}=0 .
$$

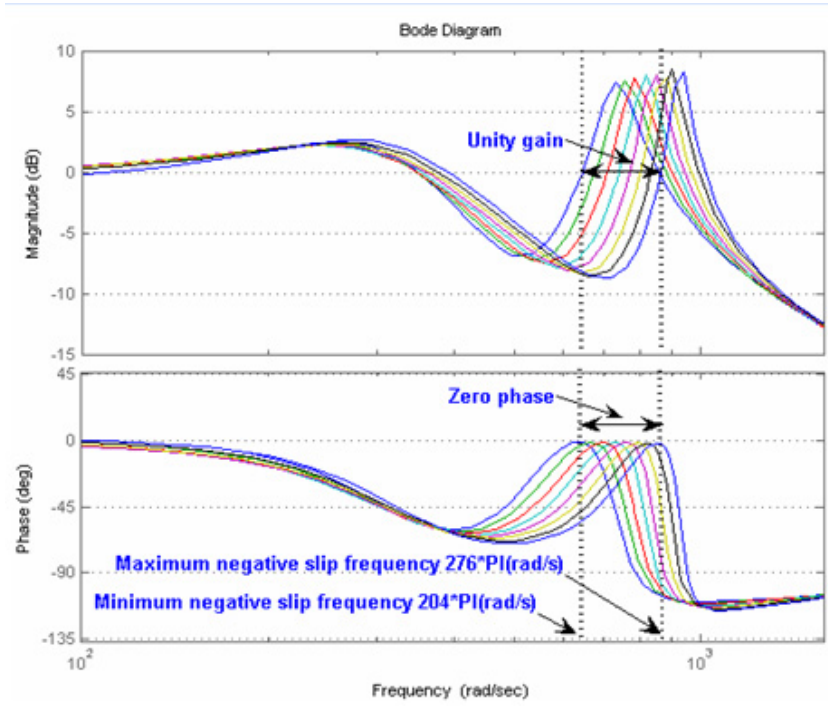

Fig. 7. Bode diagrams of the closed-loop system corresponding to the negative slip frequency variations.

It is concluded that the proposed controller can precisely regulate the current control variables with zero steady-state errors at the specific resonant frequencies $\omega_{s l}^{+}$and $\omega_{s l}^{-}$, regardless of the effect of the generator parameters $R_{r}$ and $\sigma L_{r}$.

As mentioned in the section $\mathrm{A}$, the proposed rotor current controller should be utilized in a practical DFIG system in which the rotor speed continuously changes due to variations in wind speed. Consequently, the positive and negative slip frequencies to be used in the resonant controllers also change. Assuming that the speed range of the DFIG is $\pm 30 \%$ around the synchronous speed, the variation ranges of the slip frequencies are identified by $\omega_{s l}^{+}=[-36 \pi, 36 \pi](\mathrm{rad} / \mathrm{s})$ and $\omega_{s l}^{-}=[204 \pi, 276 \pi](\mathrm{rad} / \mathrm{s})$. As demonstrated above, the accuracy of the proposed current controller mainly depends on the current tracking performance in the negative slip frequency. Therefore, Fig. 7 only shows the bode diagrams of the proposed current controller with respect to the negative slip frequency changing from $204 \pi(\mathrm{rad} / \mathrm{s})$ to $276 \pi(\mathrm{rad} / \mathrm{s})$ with a step size of $10 \pi(\mathrm{rad} / \mathrm{s})$. As can be seen, the proposed controller is able to obtain the unity gain and zero phase errors under such varying resonant frequencies. As a result, accurate control and good performance can be achieved with the proposed control strategy even thought the rotor speed is varying.

\section{Stability Problem}

A stability analysis should be considered based on the variation margin between the lowest and highest possible rotor speeds, which correspond to the sub-synchronous and the super-synchronous speeds, respectively. Fig. 8 shows the root loci of the closed-loop system in (12) with respect to the lowest sub-synchronous rotor speed, whereas Fig. 9 shows the root loci of the same system but at the highest super-synchronous rotor speed. As seen in both cases, the poles of the closedloop system lie on the left side of the s-plane. This indicates that the proposed current controller is effectively stable during rotor speed variations. Therefore, this control strategy is fully 


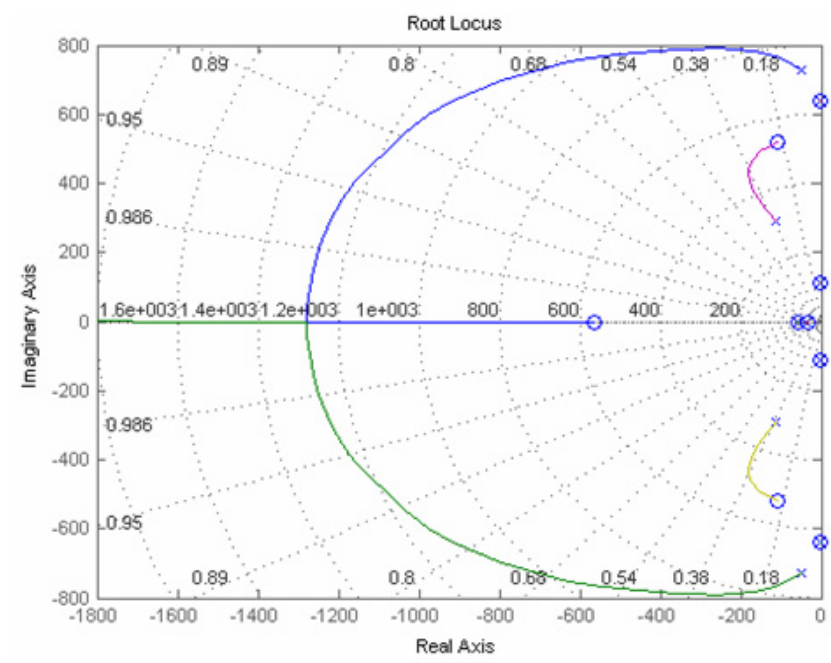

Fig. 8. The root loci of the closed-loop system with the lowest sub-synchronous rotor speed.

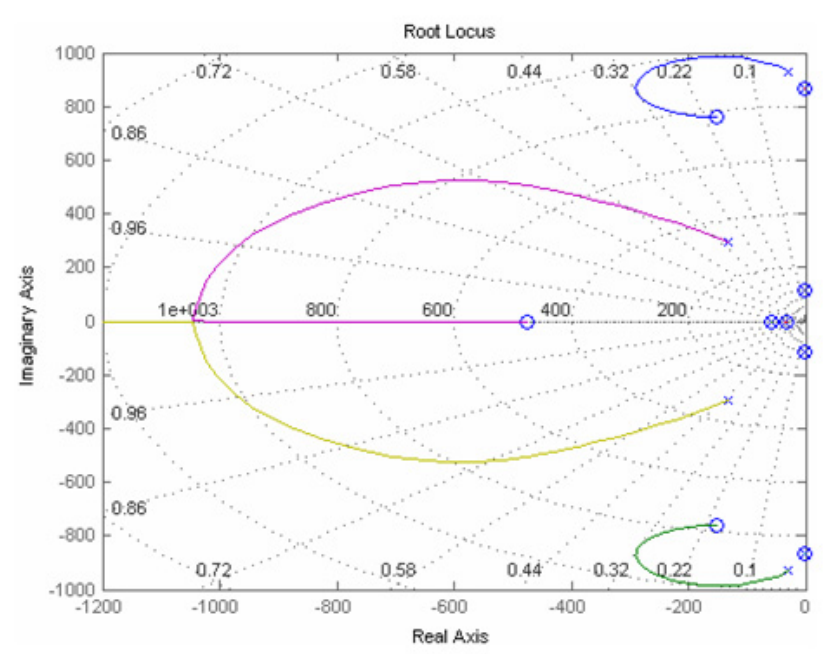

Fig. 9. The root loci of the closed-loop system with the highest super-synchronous rotor speed.

applicable to variable-speed DFIG-based wind systems.

\section{The Required Reference Rotor Voltage}

The errors between the references and the measured rotor currents are input to the P2R controllers. The required control voltages that are applied to the converters are the outputs of the proposed current controllers. The output rotor voltages are determined by:

$$
\begin{aligned}
& v_{r \alpha \beta}^{r^{\prime}}=G_{o}(s)\left(i_{r \alpha \beta}^{r *}-i_{r \alpha \beta}^{r}\right) \\
& \quad=\left(K_{p}+\frac{K_{r} s}{s^{2}+\left(\omega_{s l}^{+}\right)^{2}}+\frac{K_{r} s}{s^{2}+\left(\omega_{s l}^{-}\right)^{2}}\right)\left(i_{r \alpha \beta}^{r *}-i_{r \alpha \beta}^{r}\right)
\end{aligned}
$$

In order to improve the decoupling effect between the components of the rotor currents, the decoupling voltage components shown in Fig. 3 are added to (14), and the reference voltages for the $\alpha \beta$ components become (15) and (16), respectively. These parameters compensate for unknown quantities equivalent to the disturbances caused by the rotor

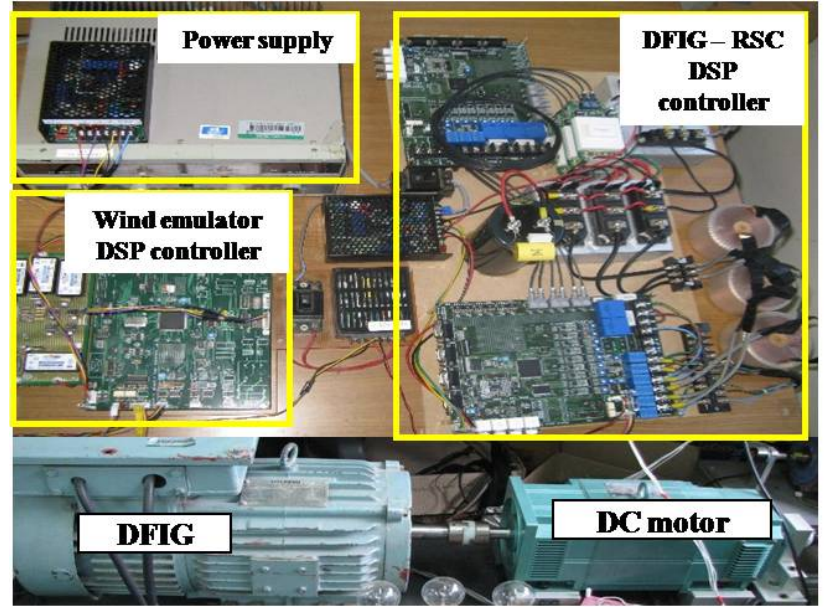

Fig. 10. Configuration of experimental setup

back-electromagnetic force (EMF).

$$
\begin{aligned}
& v_{r \alpha}^{r *}=v_{r \alpha}^{r^{\prime}}+\frac{L_{m}}{L_{s}}\left[\left(v_{s \alpha}^{r}-R_{s} i_{s \alpha}^{r}\right)+\omega_{r}\left(L_{s} i_{s \beta}^{r}+L_{m} i_{r \beta}^{r}\right)\right] \\
& v_{r \beta}^{r *}=v_{r \beta}^{r^{\prime}}+\frac{L_{m}}{L_{s}}\left[\left(v_{s \beta}^{r}-R_{s} i_{s \beta}^{r}\right)-\omega_{r}\left(L_{s} i_{s \alpha}^{r}+L_{m} i_{r \alpha}^{r}\right)\right] .
\end{aligned}
$$

These are the required rotor output voltages to be applied directly to the RSC without involving a coordinated transformation to perform the control algorithm. This is the main advantage of the controller when implementing the control scheme in the rotor rotating reference frame.

\section{SIMULATIONS AND EXPERIMENTAL RESULTS}

Simulations and experiments were carried out in order to verify the dynamic behaviors of the proposed control method. The simulation was performed using PSIM software. The experimental platform was setup in a laboratory so as to implement a DFIG system and to verify the proposed control scheme. Fig. 10 shows the experimental setup. The system consists of a $2.2 \mathrm{~kW} \mathrm{DFIG,} \mathrm{rotated} \mathrm{by} \mathrm{a} \mathrm{DC} \mathrm{motor} \mathrm{that} \mathrm{is}$ emulated as a prime mover with torque and speed control. The RSC is fed by an IGBT-based PWM inverter in which the switching frequency is $10 \mathrm{kHz}$. The system is developed with a high performance DSP TMS320F28335 by Texas Instruments. To test the dynamic performance of the proposed controller, the generator is operated with unbalanced loads. The line to the neutral stator voltage is controlled to be about $145 \mathrm{~V}$. The unbalanced loads for the tests are the one phase imbalances $30 \Omega, 50 \Omega, 50 \Omega$ for each phase. Each load subset is connected to one of the three-phase stator terminals A, B, and C.

Both the simulations and the experimental tests are implemented on the RSC of a DFIG operating at constant rotor speed of $1050 \mathrm{rpm}$. In this condition, the positive and negative slip frequency are $\omega_{s l}^{+}=15 \pi(\mathrm{rad} / \mathrm{s})$ and $\omega_{s l}^{-}=225 \pi(\mathrm{rad} / \mathrm{s})$, respectively. Fig. 11 shows the results of the rotor currents in the rotor rotating reference frame. As mentioned before, the rotor currents regulated in the rotor frame include both positive and negative sequence components. The positive sequence component $i_{r \alpha \beta+}^{r *}$ have a positive slip frequency of $7.5 \mathrm{~Hz}$ and the negative sequence component $i_{r \alpha \beta-}^{r *}$ have a negative slip 

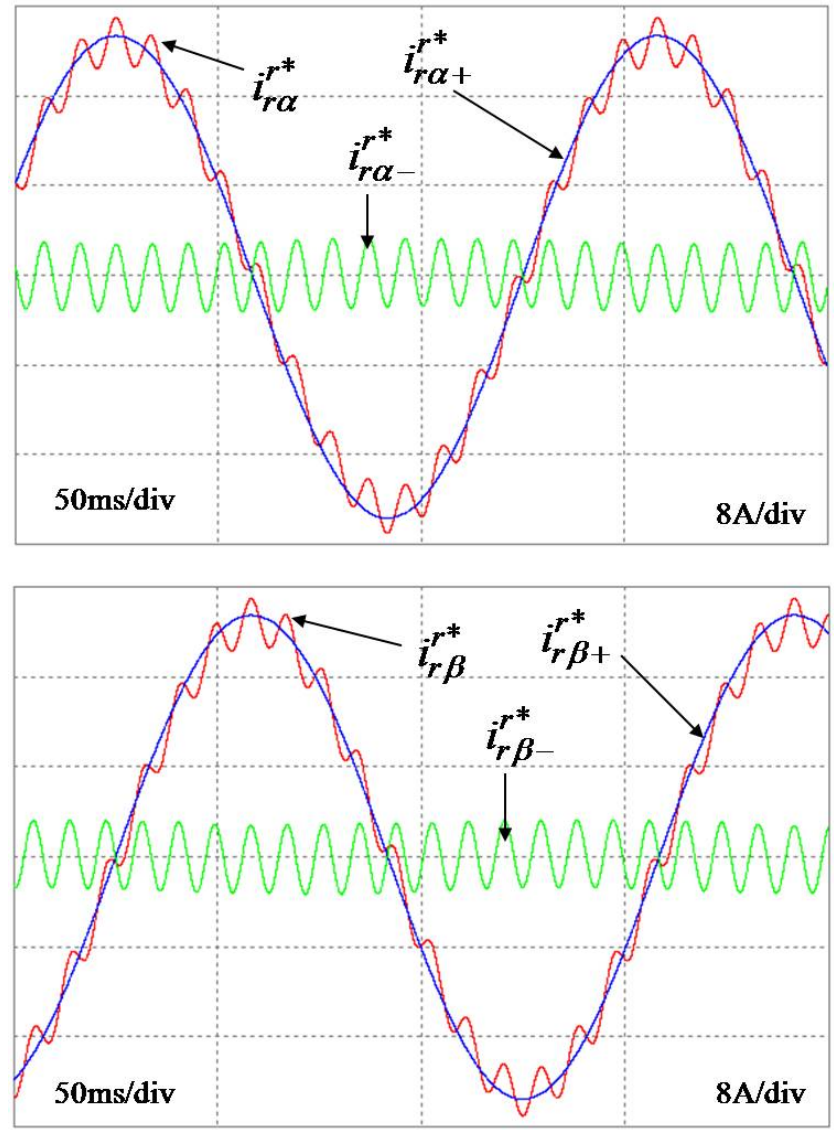

(a) Simulated results
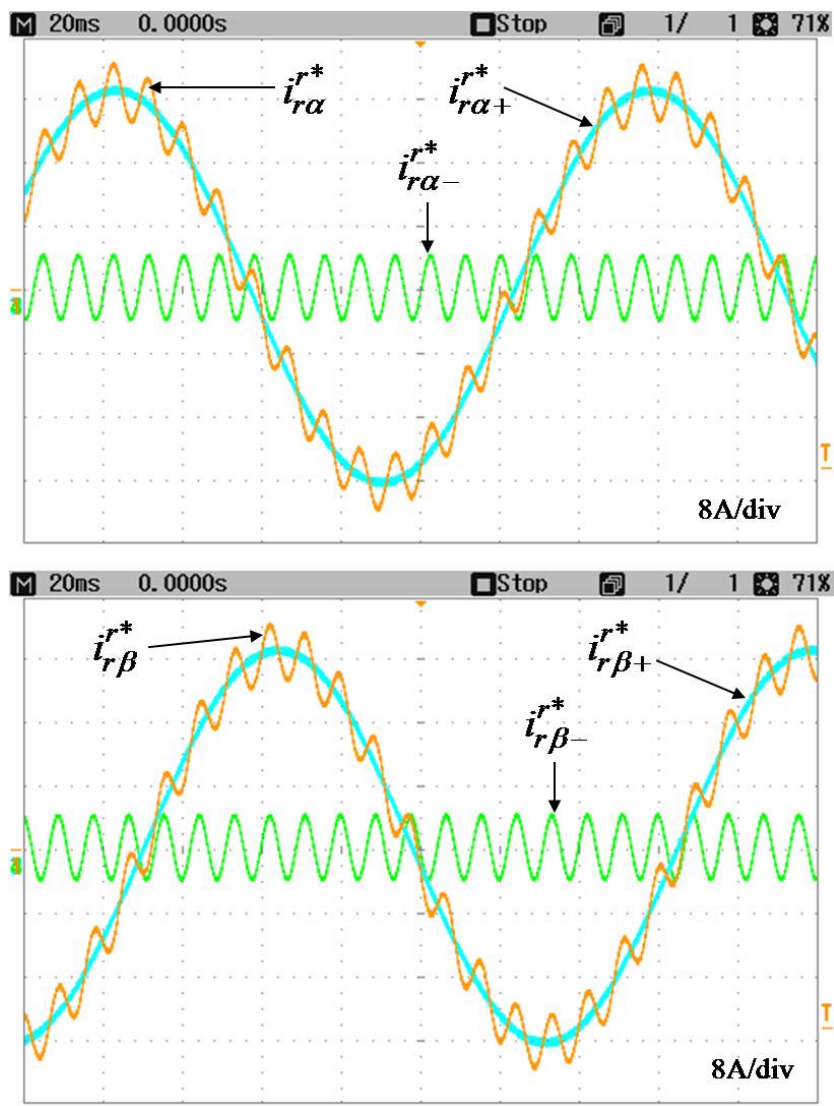

(b) Experimental results

Fig. 11. The response of rotor currents in the rotor reference frame.

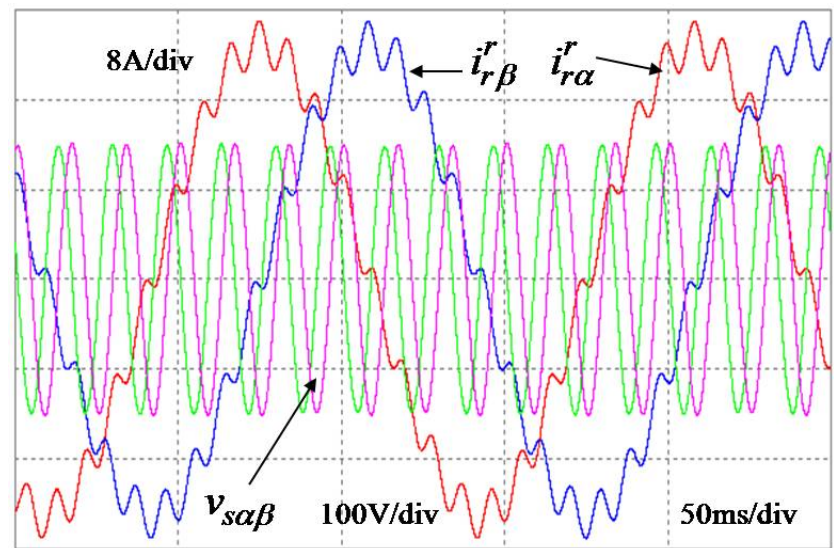

(a) Simulated results

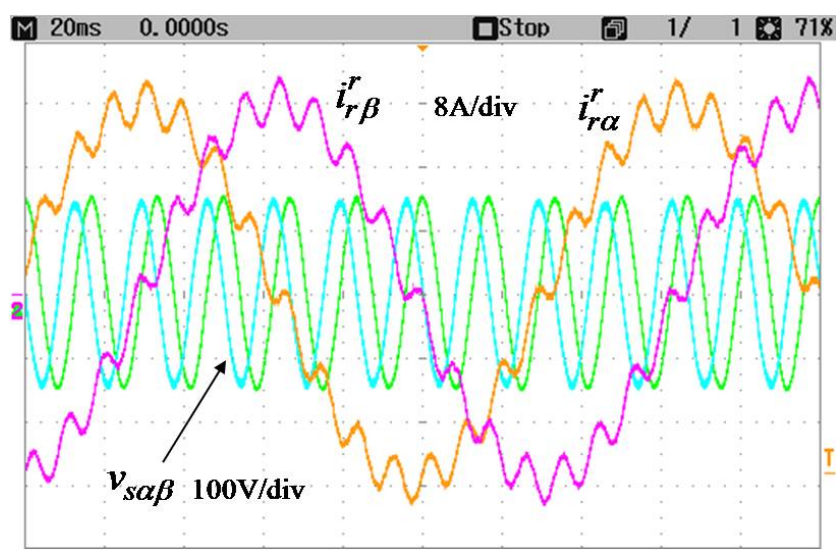

(b) Experimental results

Fig. 12. The steady state performance of the rotor currents and the balanced stator output voltages.

frequency of $112.5 \mathrm{~Hz}$. The total reference rotor currents $i_{r \alpha \beta}^{r *}$ are a combination of these two components, and hence their waveform shapes have ripples, as shown in Fig. 11. It can be seen that very good agreement can be achieved between the simulated and the experimental results.

Fig. 12 shows the steady state performance of the measured rotor currents $i_{r \alpha \beta}^{r}$ and the stator output voltages, which are balanced by the proposed control algorithm using the P2R regulator. These rotor currents are well regulated according to their respective reference values. Consequently, balanced stator voltages can also be obtained. In addition, the required output rotor voltages to be applied to the RSC are shown in Fig. 13. Like the rotor current waveforms, these rotor voltages also have both positive and negative sequence components, which are described in equations (15) and (16).

In order to test the dynamic performance of the proposed controller, experimental tests are also performed with step changes in the rotor currents in the rotor reference frame. In this test, the rotor current step changes are generated by changing the positive reference rotor currents $i_{r \alpha \beta+}^{r *}$. As shown in Fig. 14, the rotor currents are controlled accurately with a fast dynamic response for both up and down changes without any overshoots or oscillations.

Fig. 15 shows the experimental results of the dynamic performance of the rotor current when the rotor speed changes 


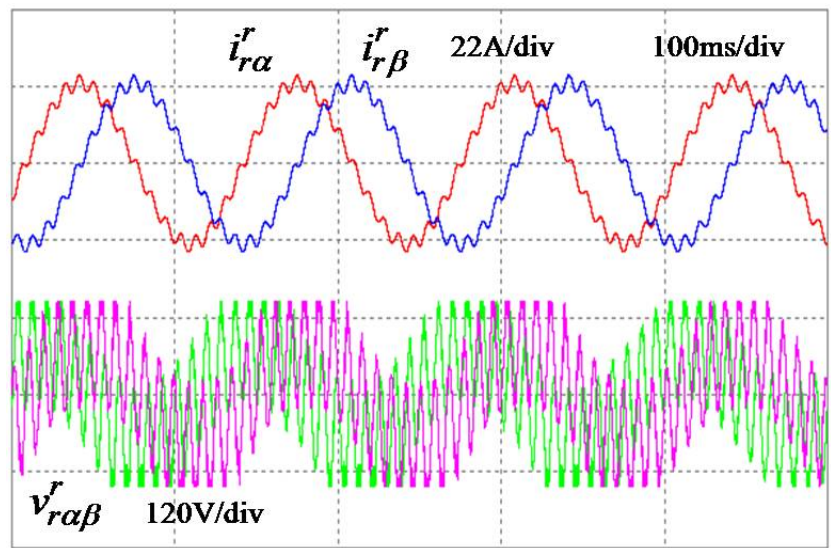

(a) Simulated results

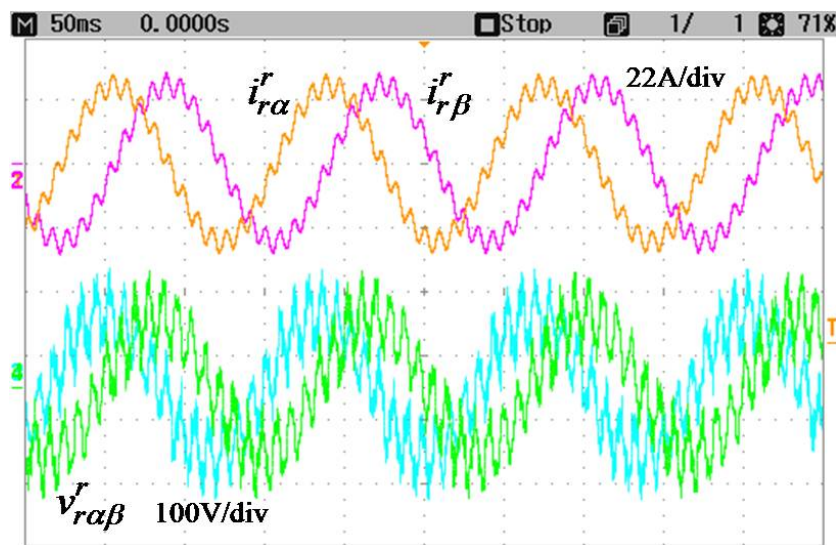

(b) Experimental results

Fig. 13. The steady state performance of the rotor currents and the required rotor voltages in the RSC.

through the synchronous speed. In this test, the rotor speed varied from $1030 \mathrm{rpm}$ to $1310 \mathrm{rpm}$, i.e., from the subsynchronous speed to the super-synchronous speed. It can be observed that the rotor current frequency, i.e., the positive slip frequency, changed instantaneously in order to generate the constant stator output voltage frequency. As shown in Fig. 15, the rotor current was regulated effectively.

To verify the effectiveness of the proposed P2R current controller, Fig. 16 shows comparative experimental results between the proposed method and the conventional PI controller under the same conditions. The PI current controller, due to its limited control bandwidth, gives very low performance when regulating the rotor current in the rotor reference frame. Meanwhile, the proposed current control with two resonant regulators provides more adequate and accurate control. Taking into consideration the steady state errors of the rotor current $\Delta i_{r \alpha}^{r}$, it is obvious that good control performance can be achieved with the proposed P2R current controller. Therefore, the proposed control scheme can obtain satisfactory results in terms of current tracking performance and unbalanced stator voltage compensation.

\section{CONCLUSIONS}

This paper has presented an effective rotor current control algorithm for an unbalanced stand-alone DFIG system. The
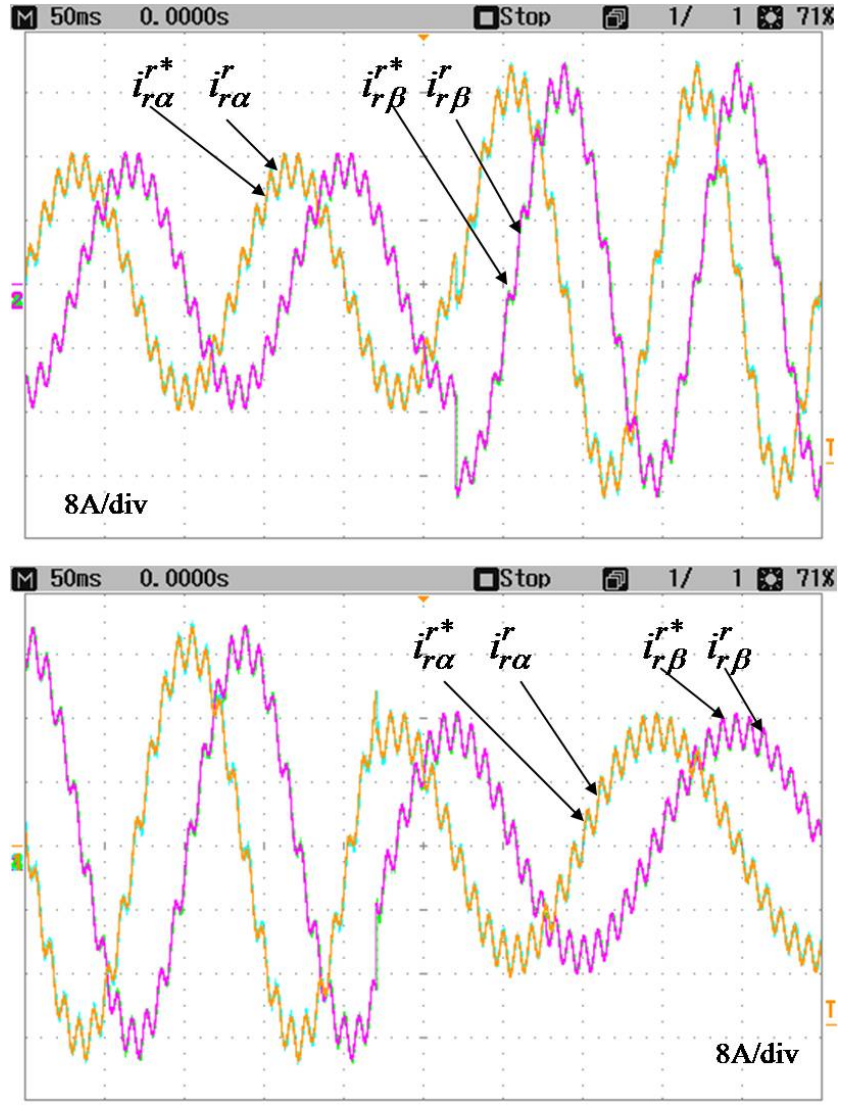

Fig. 14. The dynamic response of rotor current control (P2R) under the step change of reference current.

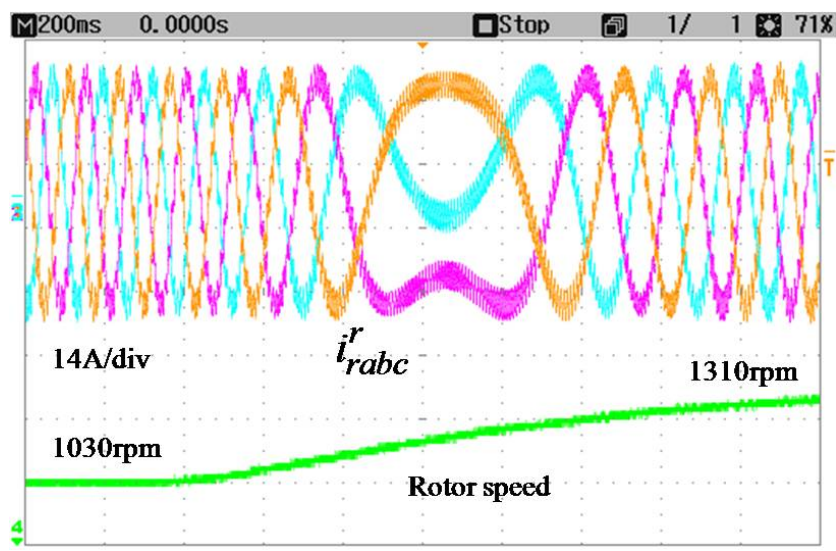

Fig. 15. Dynamic performance of the rotor current under rotor speed variations.

RSC is controlled to fully remove imbalances in the stator output voltages. The proposed current control scheme is developed based on a P2R controller tuned at the positive and negative slip frequencies. The control algorithm is examined in the rotor rotating reference frame, directly regulating the rotor current without involving coordinate transformations of the measured values. Therefore, the proposed controller can be implemented easily and accurately. Furthermore, the proposed control scheme achieves good control performance and stability as the rotor speed changes in a practical DFIG system. According to the experimental results, the P2R controller has been evaluated as a more suitable controller than 


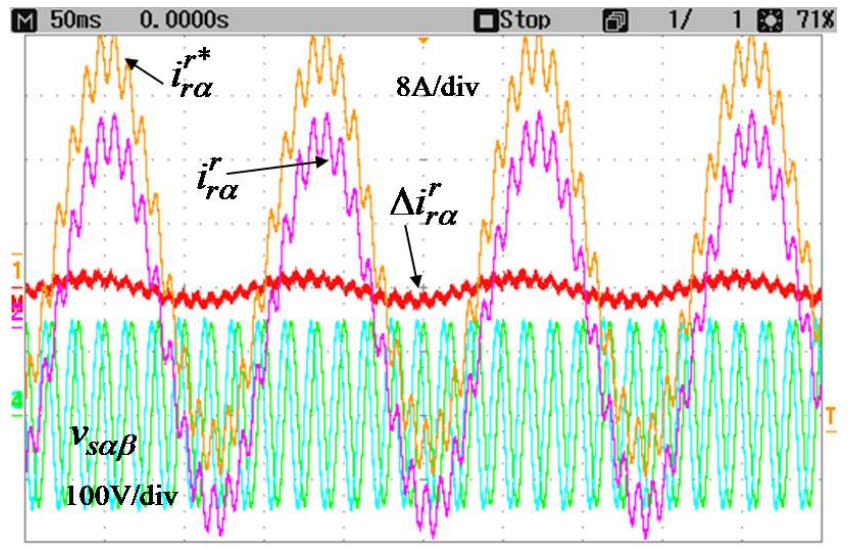

(a) PI controller.

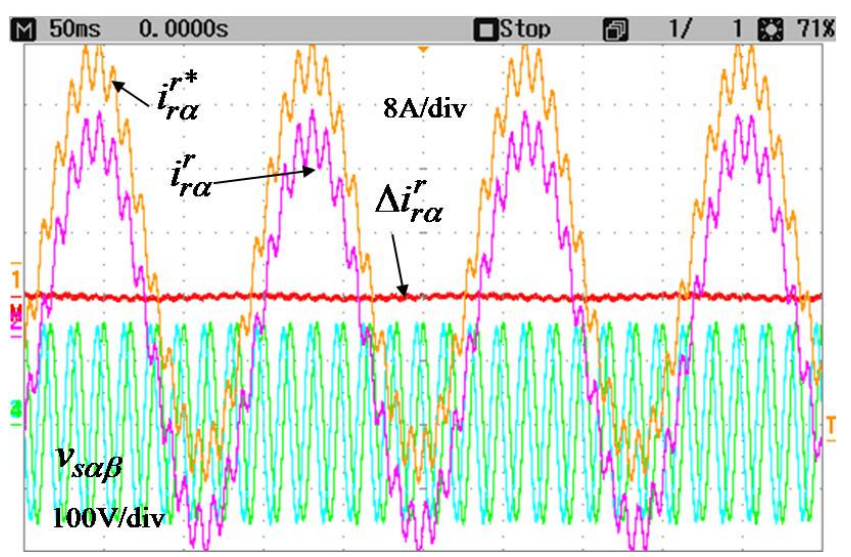

(b) P2R controller.

Fig. 16. Comparative experimental results between the PI and the P2R current controller.

a traditional PI controller for imbalance compensation. It can be concluded that under the proposed P2R current controller, the control and operation of a variable-speed DFIG system under an unbalanced load are significantly improved in terms of regulating the rotor current and eliminating a stator voltage imbalance.

\section{ACKNOWLEDGMENT}

This work was supported by the Research Fund of University of Ulsan.

\section{REFERENCES}

[1] Daniel G. Forchetti, Guillermo O. Garcia and Maria Ines Valla, "Adaptive observer for sensorless control of stand-alone doubly fed induction generator," IEEE Transactions on Industrial Electronics, Vol. 56, No. 10, pp. 4174-4180, Oct. 2009.

[2] R. Pena, J. C. Clare and G. M. Asher, "A doubly fed induction generator using back-to-back PWM converters supplying an isolated load from a variable speed wind turbine," IEE Proc. Electric Power Applications., Vol. 143, No. 5, pp. 380-387, Sep. 1996.

[3] S. Muller, M. Deicke, R.W, and De Doncker, "Doubly fed induction generator system for wind turbines," IEEE Industry Application Magazine, Vol. 8, No. 3, pp. 26-33, May 2002.

[4] Arantxa Tapia, Gerardo Tapia, J. Xabier Ostolaza, and Jose Ramon Saenz, "Modeling and control of a wind turbine driven doubly fed induction generator," IEEE Transactions on Energy Conversion, Vol. 18, No. 2, pp. 194-204, Jun. 2003.

[5] Lie Xu, Yi Wang, "Dynamic modeling and control of DFIG-based wind turbine under unbalanced network conditions," IEEE Transactions on Power Systems, Vol. 22, No. 1, pp. 314-323, Feb. 2007.

[6] Yi Zhou, Paul Bauer, Jan A. Ferreira, and Jan Pierik, "Operation of grid-connected DFIG under unbalanced grid voltage condition," IEEE Transactions on Energy Conversion, Vol. 24, No. 1 pp. 240-246, Mar. 2009.

[7] David Santos-Martin, Jose Louis Rodriguez-Amenedo, and Santiago Arnalte, "Direct power control applied to doubly fed induction generator under unbalanced grid voltage conditions," IEEE Transactions on Power Electronics, Vol. 23, No. 5, pp. 2328-2336, Sep. 2008.

[8] Gonzalo Abad, Miguel Angel Rodriguez, Grzegorz Iwanski, and Javier Poza, "Direct power control of doubly fed induction generator based wind turbines under unbalanced grid voltage," IEEE Transactions Power Electronics, Vol. 25, No. 2, pp. 442-452, Feb. 2010.

[9] R. Pena, et al, "Control system for unbalanced operation of standalone doubly fed induction generator", IEEE Transactions on Energy Conversion, Vol. 22, No. 2, pp. 544-545, Jun. 2007.

[10] R. Pena, et al, "Control strategy for a doubly fed induction generator feeding an unbalanced grid or stand-alone load," Electric Power Systems Research, Jul. 2008

[11] R. Teodorescu, et al, "Proportional-resonant controllers and filters for grid-connected voltage source converters," Electric Power Application, IEE Proceedings, Vol. 153, No. 5, pp. 750-762, Sep. 2006.

[12] Marco Liserre, Remus Teodorescu, and Frede Blaabjerg, "Multiple harmonics control for three-phase grid converter systems with the use of PI-RES current controller in a rotating frame," IEEE Transactions on Power Elecronics, Vol. 21, No. 3, pp. 836-841, May 2006.

[13] D. N. Zmood and D. G. Holmes, "Stationary frame current regulation of PWM inverters with zero steady state error," IEEE Transactions on Power Electronics, Vol. 18, No. 3, pp 814-822, May 2003

[14] Van-Tung Phan, Hong-Hee Lee, and Tae-Won Chun, "An improved control strategy using PI-resonant controller for unbalanced stand-alone doubly fed induction generator," Journal of Power Electronics, Vol. 10, No. 2, pp. 194-202, Mar. 2010.

[15] Marian P. Kazmierkowski, R. Krishnan, F. Blaabjerg, Control in Power Electronics: selected problems, Academic Press, 2002.

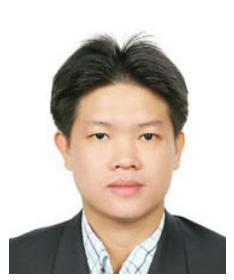

Van-Tung Phan was born in Binh Dinh province, Vietnam, in 1982. He received his B.S. in Electrical Engineering from the University of Technology, Ho Chi Minh city, Vietnam, in 2005. Since September 2005, he has been a Ph.D candidate in the School of Electrical Engineering, University of Ulsan, Korea. His research interests include power electronics, electrical machine drives, and advanced control techniques applied to DFIG and PMSG wind power systems.

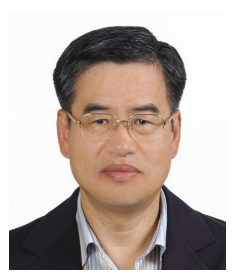

Hong-Hee Lee (M'96) is a Professor in the School of Electrical Engineering, University of Ulsan, Ulsan, Korea. $\mathrm{He}$ is also the Director of the Network-based Research Center (NARC). He received his B.S., M.S., and Ph.D. in Electrical Engineering from Seoul National University, Seoul, Korea, in 1980, 1982, and 1990, respectively. His current research interests include power electronics, network-based motor control, and control networks. He is a member of the Institute of Electrical and Electronics Engineers (IEEE), the Korean Institute of Power Electronics (KIPE), the Korean Institute of Electrical Engineers (KIEE), and the Institute of Control, Automation, and Systems Engineers (ICASE).

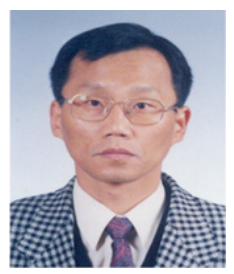

applications.
Tae-Won Chun was born in Korea in 1959. He received his B.S. in Electrical Engineering from Pusan National University in 1981, and his M.S. and Ph.D. in Electrical Engineering from Seoul National University in 1983 and 1987, respectively. Since 1986, he has been a Faculty Member in the Department of Electrical Engineering, Ulsan University, where he is currently a Full Professor. His current research interests include the control of electrical machines, power converter circuits, and industrial 